\title{
Creating Interest in Textiles: A Pedagogical Perspective
}

\author{
Shweta L Reddy* \\ Texas Christian University, USA
}

*Corresponding author: Shweta L Reddy, Interior Design and Fashion merchandising,

Texas Christian University, USA.

Received Date: November 26, 2018

Published Date: December 05, 2018

\begin{abstract}
This paper presents pedagogical insight gained from instructing 'fundamentals of textiles', 'textile testing and analysis' and 'sustainability in fashion' to students of fashion merchandising. The challenge for any teacher is to capture student interest and to keep students interested in the topic. The paper makes an argument that study of textiles becomes valuable to students when they become aware of textiles being a confluence of science, technology, art, culture and sustainability.
\end{abstract}

Keywords: Pedagogy; Textile; Culture; Technology; Innovation; Sustainability

\section{Introduction}

I did not think much about textiles being interdisciplinary until I started teaching textiles to fashion merchandising majors. Over the twelve years, many students have enjoyed taking the textile fundamentals course I instruct, and I am grateful for it. It was three years ago, a student of mine, came to my office to tell me that she found textiles fascinating because textiles incorporate both art and science. It was then, that I started paying attention to the remarks I make during class drawing their attention to the fact that certain cellulosic and animal fibers grow in specific regions because the natural environment supports the growth of certain plants or rearing of certain species of animals, people in different regions develop products and methods to work with the fibers they cultivate locally, history of rayon, acetate, nylon, polyester and how these fibers were developed to meet the changing needs of people, the skill required to hand weaving and use of handloom for making exquisite textiles, the emphasis on hand dying and hand printing techniques from Asia.

I was not conscious that I carried with me into the classroom, respect for science, my admiration for different dying and printing techniques and how a greige fabric could be transformed aesthetically. The things I appreciate about textiles informs the way I instruct. My aim all along has been to get the fashion merchandising students in my classroom to develop an appreciation for textiles without being intimidated by the science and technology behind it. I realize today that the content I teach is not as important as how it is received by the students. Students must use the information presented to them by a teacher and transform it to knowledge, but this can only happen if they can enjoy learning about the topic.

\section{Materiality of textile}

The textile woven by a traditional weaving community may have an economic value determined by demand, supply, artistry (skill of weaving) and utility, but the textile also carries symbolic meaning. Weaving communities engaged in creative and productive process of making traditional textiles. In many parts of the world, textiles embody the weaver's or weaving communities' beliefs, histories, folklore, motifs, and design sensibilities. Therefore, textile products are important representations of a given community and their material culture. A community of weavers engaging in making traditional textiles is essential to keeping textile artistry alive. "Cultural products are derived from distinctive characteristics of social groups: material, intellectual, spiritual and emotional characteristics. These elements of artistic heritage developed by individuals reflect the cultural artistic expression of the community, either in a verbal or a material form" [1].

\section{Cultural understanding of textile}

The textiles weavers local to a specific place in a country or a region of the world engage in creating textiles that are influenced by their aesthetics and sensibilities. The selection of colors, the choice of yarns, the patterns, design layout, the interlacing of the yarns and motifs used on/in the textile is the art aspect of textile 
weaving. The awareness of textiles being intricately enmeshed with the local culture should not be a farfetched idea for students. Textile woven by indigenous weavers across different parts of the world are unique because of what they represent which is then described by scholars as characteristics or distinguishing features in terms of colors, the motifs and layout. A few years ago, when I was informing my students about Belgium Tapestry, one of my students asked, 'why would one spend so much time and effort to make a tapestry?' and my response was, "why would anyone spend hours to paint on canvas? It is for the same reason". The hand weaving of textiles is as unique in its artistry as water color painting or oil painting. Unfortunately, young consumers living in urban cities in developed and developing countries may think of textiles only as a raw material for fashion apparel.

Growing up in India and having seen different textiles being made uniquely by weavers from different parts of the country, it was natural for me to appreciate the artistry and skill of the weavers. One of the reasons for this appreciation could be that many common clothing articles in India were draped textile such as Shawls, Dupattas, Saris, Lungi, Veshti, Mel Veshti, and Mundu and thus the textile could be appreciated in its entirety. Also, shawls and saris woven in different parts of India are unique in their quality of yarns, fibers, motifs, colors, design and weaving style.

\section{Textile is transformative}

"What inevitably happens with art and technology is that an invention made for historical reasons then turns out to suggest new possibilities that were not even thought about prior to the technology existing" [2]. The scientific and technological advancements provide people with possibilities that undoubtedly transform their lives. For example, p-aramid and m-aramid, also popular as Kevlar ${ }^{\circledR}$ and Nomex ${ }^{\circledR}$ protects the wearer and these kind of developments in fiber science and technology have impacted the expectations of safety measures for professionals who undertake personal risk to safeguard other individuals. Furthermore, innovation of polymers and fibers in medical devices focusing on wound dressing, compression therapy, and life-saving implants propels newer innovations.

When teaching fashion merchandising and fashion design students about different fibers, it is best to provide students with an understanding that the development of fibers corresponds with technological changes and the evolving needs of people. Textiles fibers are developed with an aim to fulfill needs or requirement of a given industry and when these fibers are commercialized it can cater to a larger consumes base. For instance, the needs and requirements of civil engineering results in the development of geotextiles, the needs generated in the health care industry result in research and developments in odor absorbent and antimicrobial dressings, commercializing polyester fulfilled the need for easy wash care when large number of women in western world started taking employment. These innovations may be initiated to fulfill a specific need, but when commercialized these innovations have wider applications. For example, progress made in odor absorbent and antimicrobial dressings would likely inform product improvements in footwear and sportswear.
Teaching textiles and fiber science cannot be limited to technical or historical approach because fashion merchandising student also need to understand the consumer experience. For instance, today in developed countries most athletic wear are made of manmade fibers. The explanation for this might be that fibers used in workout clothes do not require absorbency, but wicking ability and manmade fibers can be modified to have improved wicking during manufacture. An average consumer may not know the difference between the two concepts of absorbency and wicking or the fiber technology that makes some synthetic fibers better for athletic wear, yet consumers know this by experience. The consumers may not know the terminology used by textile experts, but these consumers have been impacted and so has their product expectations.

\section{Textile is more than fiber science}

When instructing basic textiles or fundamentals of textiles to an audience that uses the knowledge of textiles to understand the characteristics of a clothing product, it is crucial for the instructor of textiles to recognize that science is only one aspect of textiles. Using organic chemistry terminology and providing scientific explanations for fiber or textile behavior can intimidate most fashion merchandising and fashion design students. To this population of students using textile science terminology comes across as high handed. It is the instructor's responsibility to overcome this barrier because as instructor of textile, one cannot do without using terminology such as hygroscopic, polymerization, and other terms that are crucial in explaining fiber properties and characteristics. However, teaching textile to students who have chosen a nonscience discipline, the approach that has worked for me has been to encourage students to make connections between textile science components with practical and relatable explanations of different fiber and textiles behavior.

\section{Textile sustainability and technology}

Textile industry is undergoing change and preparing for further changes as sustainability becomes an essential consideration for production of all products. As an instructor addressing the topic of sustainability, it is essential to keep up with the changes taking place in textile industry and to convey these developments to students. To create interest in students, I remark on the demerits of methods used in fiber and textile production or methods used for coloration. I allow students to think of the many challenges faced by the textile and fashion industry when incorporating sustainable model and then introduce them to the sustainable practices being used in the fiber and textile industry.

As cradle- to-cradle principles gain stronger foothold, changes in textile industry will be demanded by all industries using textiles. For example, the fashion industry depends on textiles as raw material for footwear and fashion apparel. Producing sustainable fibers and textiles would by default help improve sustainability of a fashion apparel and footwear products. In the near future, all advancements made in fiber and textile production will have to meet requirements such as, low carbon impact and/ or positive environmental impact. All innovations will have to consider product end-of-life, where textile components will be compostable 
or transformed into useful material or resource in making other products.

One of the earliest industries to propel the industrial revolution was the textile industry [3]. Technological innovations such as the ginning machines, technical improvements in looms enabling fabric structures, the invention of synthetic dyes and fluorescent colors, the development of regenerated and synthetic polymers addressed the needs of the time [3]. Technological innovations in the textile industry ushered the industrial revolution, technology will once again be the key to its transformation. Challenges like toxicity, generation of waste, provenance and transparency are likely to be addressed by technological improvements and innovations. Technologies such as waterless dyeing, 3D printing, self-repairing textile, self-cleaning textiles, and apps such as 'Making' encourage designers to select materials that have low environmental impact. Not only textile technology but technology to trace sustainability of businesses and products made in the textile and fashion industry will bring changes in our society and further propel sustainable fiber innovations, use of cleaner and sustainable processes and methods in textile and apparel creation, consumption, and end- of -life product disposal [4].

\section{Textile developments and advancements}

At present, interactive electronic textile is being developed for health, communication, entertainment and safety [5], the use of nanotechnology in the development of textile material for improving function of textile and apparels [6], the development and advancements in smart textiles. Smart textiles are likely to revolutionize and transform apparel industry when commercialized [7]. Smart fabrics are human centered, and the technologies are being designed to regulating physical response of the human body to the external environment such as regulating body temperature and vibrating muscle [8]. The applications of nanotechnology imply materials designed to interact at molecular level and in case of in medicine and physiology the materials and devices would interact with the body at subcellular level [9]. The use of smart textiles, interactive textile and Nano-textiles in the fashion industry allows further application of these textile to broad range of new products. When commercialized, these innovative textiles will be consumed in variety of ways both by consumers and those engaged in product development. The innovative ways in which these textiles would be used will further drive product innovation and development. These innovations present a challenge for agencies such as Consumer Product Safety Commission (CPSC) that test product safety.

The challenges of developing tests and test methods for new innovative textile-based products is addressed in textile testing course. For the final assignment, students enrolled in this course are required to research one innovative textile-based product. For the product selected, student research at least three tests performed on the product and corresponding testing methods. If students are not able to find preexisting tests and test methods, then students provide details of tests developed by the company when testing the product and the corresponding test method. This assignment is intended for students to realize that new or innovative products launched in the market may not be able to use preexisting tests and test methods. This assignment also demonstrates to the students that developing tests and test methods requires keen understanding of testing standards, textile behavior, product features, and specifications.

\section{Conclusion}

Students enroll in variety of courses to fulfill requirements for fashion merchandising program and fashion design. Students can be made aware of the interdisciplinary nature of textiles explicitly in courses such as introductory course to textiles, garment construction, history of fashion, product development, sociopsychological aspect of clothing, apparel/ fashion sustainability, and textile testing. This awareness of textiles allows students to develop an appreciation for textile as a material that can fulfill multiple human needs such as comfort, aesthetics, safety and protection. Soon, advancements in interactive electronic textiles will also fulfill the need for communication and entertainment. Textile advancements such as smart textile, Nano textile and interactive electronic textile are markers of the development in science, changing lifestyles, shift in culture, and human advancement.

\section{Acknowledgement}

None.

\section{Conflict of Interest}

No Conflict of Interest.

\section{References}

1. Rusu A A (2011) Traditional textile art between sustainability and economic growth. Review of Applied Socio-Economic Research 2: 160166.

2. Weium F, Boon T (2013) Material culture and electronic sound (Artefacts: Studies in the History of Science and Technology). Smithsonian Institution Scholarly Press, USA.

3. Scaturro S (2008) Eco-tech fashion: rationalizing technology in sustainable fashion. Fashion Theory 12(4): 469-488.

4. Payne A (2017) Fashion futuring in the anthropocene: sustainable fashion as "taming" and "rewilding. Fashion Theory: 1-19.

5. Meoli D, May-Plumlee $T$ (2002) Interactive electronic textile development: a review of technologies. J Textile and Apparel Technologies and Management 2(2): 1-12.

6. (2018) Nano-textiles show glimpse of great future.

7. Reuters (2018) Global smart fabrics in fashion and entertainment market 2018- by type of product, function, material, region-growth, trends, and forecasts to 2023.

8. Bae SY, Wooldridge G D (2018) Smart fashion and wearable technology: opportunities and challenges for future growth. Journal of Textile Science and Fashion Technology 1(3): 1-2.

9. Sahoo SK, Parveen S, Panda JJ (2007) The present and future of nanotechnology in human health care. Nanomedicine 3(1): 20-31. 